\title{
Creation of Methods for Automated Determination of Forest Parameters Based on Data from UAVS
}

\author{
Roman Aleshko, Ksenia Shoshina, Irina Vasendina, Aleksandr Bogdanov, Aleksandr Karpov
}

\begin{abstract}
The article presents a scientific study on the use of aerial photographs obtained by unmanned aerial vehicle (UAV), for the automated collection of data on forest resources in the taiga forests of the European North of Russia.

On the example of the trial plot, a technique is described for automated allocation of crown contours, calculation of the trunk diameter and timber stock in the forest area. The methodology used morphological methods for processing digital images, geographic information tools for representing and processing spatial information, as well as the results of statistical observations of leading scientists in the field of forestry.

The results have been verified in the field in several plots. The technique is applicable to automate the process of thematic interpretation of orthorectified aerial photographs with a spatial resolution of five to ten centimeters per pixel. The experiments presented in the article were carried out on images of forests in the north of the European part of Russia. The research results are used for regular automated updating of information on forest resources.
\end{abstract}

Keywords: digital image processing, aerial photographs, satellite images, UAVs, forest area, updating of information.

\section{INTRODUCTION}

The study of taiga forests using remote sensing data is carried out over a long period of time in the articles of many scientists [1-3]. Most of the work in determining the parameters of forest stands based on remote sensing data was focused on satellite imagery data of medium and high resolution [4-8]. Moreover, data from spacecraft do not allow determining the characteristics of forests with the necessary accuracy.

Increasingly, there are efforts aimed at the development of alternative methods for the preparation and updating of forest

Revised Manuscript Received on December 30, 2019.

* Correspondence Author

Roman Aleshko*, Northern (Arctic) Federal University, Arkhangelsk, Russia. Email: r.aleshko@gmail.com

Ksenia Shoshina, Northern (Arctic) Federal University, Arkhangelsk, Russia.

Irina Vasendina, Northern (Arctic) Federal University, Arkhangelsk, Russia.

Aleksandr Bogdanov, Northern Research Institute of Forestry, Arkhangelsk, Russia.

Aleksandr Karpov, Northern (Arctic) Federal University, Arkhangelsk, Russia.

(C) The Authors. Published by Blue Eyes Intelligence Engineering and Sciences Publication (BEIESP). This is an open access article under the CC BY-NC-ND license (http://creativecommons.org/licenses/by-nc-nd/4.0/) data [9-12]. One of the priority and cost-effective areas, from the point of view of the obtained cartographic and attributive material, is data processing from UAVs. Moreover, the manual processing of aerial photographs to solve the problems of forest inventory is a very time-consuming and laborious task. Therefore, the creation of new automated techniques and processing algorithms is required.

\section{METHODOLOGY}

The main interpretive features in the study of aerial images are: size, tone, shape of tree crowns [1]. An analysis of these characteristics was carried out using computer vision methods. [13-16]. Fig. 1 shows the initial fragment of the UAV image, which depicts a forest plot with a spatial resolution of 5 centimeters per pixel. There are crowns of trees and inter-crown spaces on image.

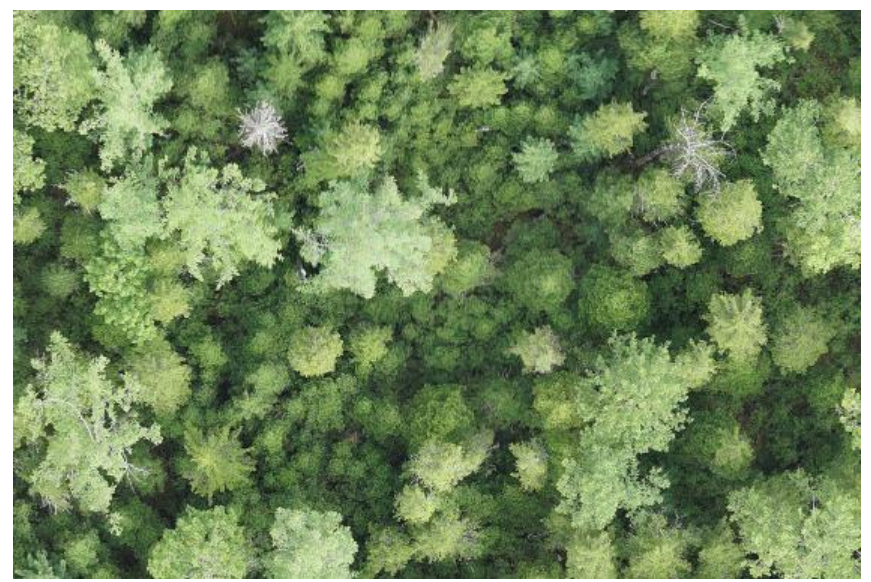

Figure 1 - An example of digital image from UAV

\section{A. Highlighting of contours}

The original image was presented in grayscale. An alternating sequential filtering (ASF) with a window size of 2 pixels was applied to the image fragment. This image filtering method relates to algorithms for morphological processing of a raster. [17].

The next step was to determine the regional maxima of the raster brightness.

Then the watershed segmentation was applied to the image. When using this method, the raster is represented as a three-dimensional surface, the points of which are given by two spatial coordinates, and the brightness level acts as a height. 


\section{Creation of Methods for Automated Determination of Forest Parameters Based on Data From UAVS}

Application of the segmentation algorithm for watersheds often leads to the effect of excessive segmentation caused by noise and local extrema in the image. This means getting a huge number of areas allocated during segmentation.

The approach used to control segmentation is based on the idea of markers [18, 19].

A marker is a connected component that belongs to an image. In our case, the previously selected local maxima of the brightness of the raster were set as markers. The result of the proposed methodology will be a set of tree crown contours obtained automatically (Fig. 2). After obtaining the contours of the crowns, the procedure of vectorizing them was carried out with the aim of integration and subsequent processing in the geographic information system.

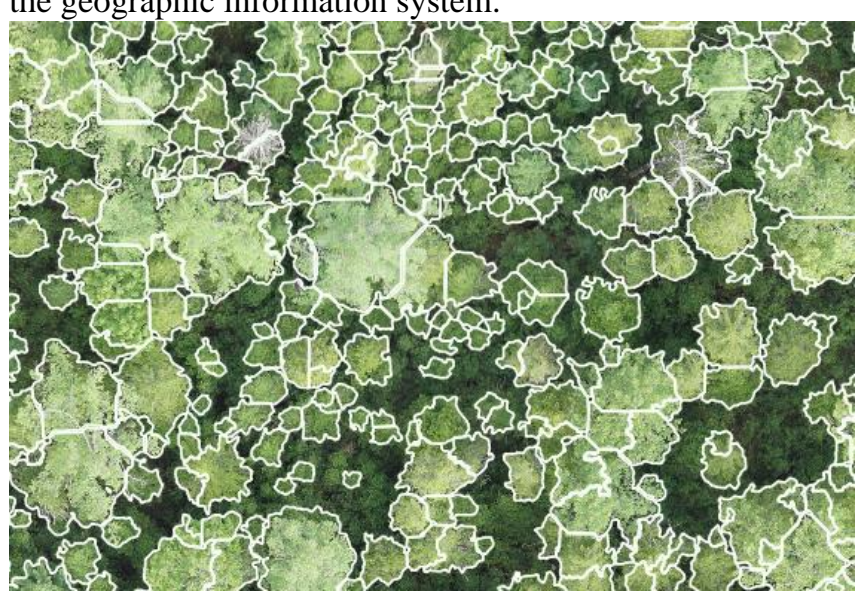

Figure 2 - Highlighted contours

\section{B. Identification of species}

At the next stage of image processing, tree species were divided into deciduous (birch, aspen) and coniferous (spruce, pine).

In the field it was marked model trees, mapped their coordinates. For various species, the average brightness of the pixels of the digital image was calculated, which allowed the classification of the contours. (Fig. 3).

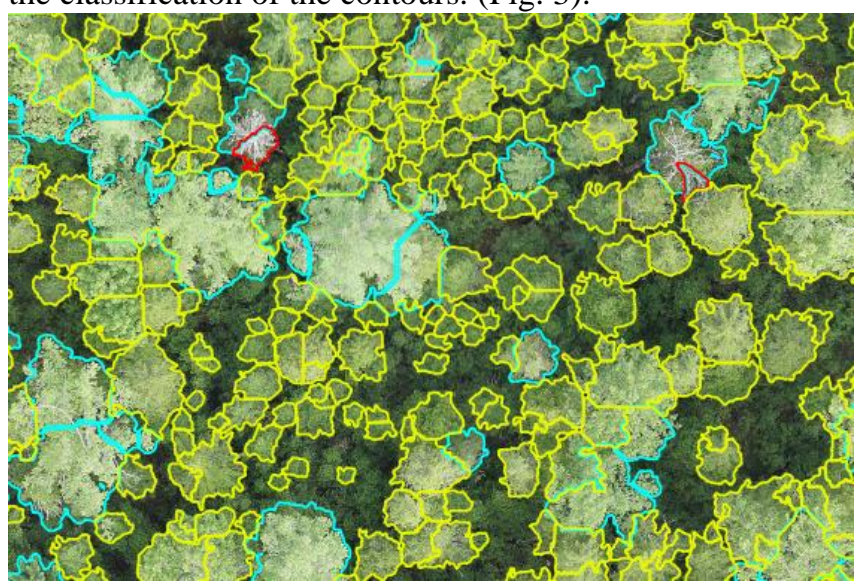

Figure 3 - Classified contours

\section{Wood stock calculation}

One of the most important parameters in assessing forest resources is the wood stock. Information on the diameter of the crown is enough to evaluate this parameter.

The diameter of the crown can be found from the area of the crown. Based on the fact that the crown has a rounded shape, the diameter of the crown can be calculated by the following formula:

$$
\mathrm{D}_{c r}=\sqrt{\frac{4 \mathrm{~S}}{\pi}},
$$

Studies [20] established the relationship of tree crowns with other taxation parameters for different types of forest. For the transition from the diameter of the crown to the diameter of tree trunk at height of $1.3 \mathrm{~m}\left(\mathrm{~d}_{1,3}\right)$ the formula is proposed:

$d_{1,3}=7,86 D_{c r}-0,09 D_{c r}^{2}-5,22$,

where $d_{1,3}$ is the diameter of the tree trunk at the height of $1.3 \mathrm{~m}, \mathrm{~cm}$;

$\mathrm{D}_{\mathrm{cr}}$ - tree crown diameter, $\mathrm{m}$.

One of the most significant parameters of forest stands is the wood stock $\left(\mathrm{m}^{3} / \mathrm{ha}\right)$. With the help of previously obtained diameter values at the height of $1.3 \mathrm{~m}$, it is possible to calculate the volume of tree trunks according to the Densin formula:

$V=0,001 \cdot d_{1,3}^{2}$

where $\mathrm{V}$ is the volume of the tree, $\mathrm{m} 3$.

The formula gives satisfactory results for tree trunks with height of about 25 meters. In other cases, volumes must be increased by 3\% for each meter in excess of $25 \mathrm{~m}$, and reduced by $3 \%$ for each meter below.

Then the stock was calculated by the formula [21]:

$M=n \cdot V$,

where $\mathrm{M}$ - wood stock, $\mathrm{m}^{3} / \mathrm{ha}$;

$\mathrm{n}$ - the number of trees in steps of thickness, pcs.

\section{RESULT}

As an object of research, a plot located in the Shenkursk, (Arkhangelsk region, Russia) was chosen. There was a trial area of 0.83 ha. The result of determining the wood stock according to the method described previously is shown in Table 1.

Table 1 - Result of determining of wood stock

\begin{tabular}{|c|c|c|c|c|c|}
\hline \multirow{2}{*}{$\begin{array}{c}\text { Steps of } \\
\text { thickness, } \\
\mathrm{cm}\end{array}$} & \multirow{2}{*}{$\begin{array}{c}\text { Number } \\
\text { of trees, } \\
\text { pcs }\end{array}$} & \multicolumn{2}{|c|}{$\begin{array}{c}S \text { of tree cross } \\
\text { section, } \mathrm{cm}^{2}\end{array}$} & \multirow[b]{2}{*}{$\begin{array}{l}\text { Wood } \\
\text { stock }\end{array}$} & \multirow{2}{*}{$\begin{array}{c}\text { Wood } \\
\text { stock } \\
\text { per ha }\end{array}$} \\
\hline & & one tree & $\begin{array}{c}\text { all } \\
\text { trees }\end{array}$ & & \\
\hline 12 & 7 & 133,6 & 935,2 & 7,2 & 8,7 \\
\hline 16 & 20 & 199,3 & $\begin{array}{c}3 \\
986,0 \\
\end{array}$ & 5,8 & 7,0 \\
\hline 20 & 46 & 312,8 & $\begin{array}{c}14 \\
388,8 \\
\end{array}$ & 21,6 & 26,0 \\
\hline 24 & 33 & 451,2 & $\begin{array}{c}14 \\
889,6 \\
\end{array}$ & 33,7 & 40,6 \\
\hline 28 & 24 & 613,8 & $\begin{array}{c}14 \\
731,2 \\
\end{array}$ & 24,9 & 30,0 \\
\hline 32 & 13 & 789,7 & $\begin{array}{c}10 \\
266,1 \\
\end{array}$ & 15,0 & 18,0 \\
\hline 36 & 6 & 979,1 & $\begin{array}{c}5 \\
874,6 \\
\end{array}$ & 7,6 & 9,2 \\
\hline 40 & 1 & 1314,0 & $\begin{array}{c}1 \\
314,0 \\
\end{array}$ & 2,7 & 3,2 \\
\hline Total & 150 & 4793,5 & $\begin{array}{c}66 \\
385,5 \\
\end{array}$ & 118,4 & 142,6 \\
\hline
\end{tabular}

Published By:

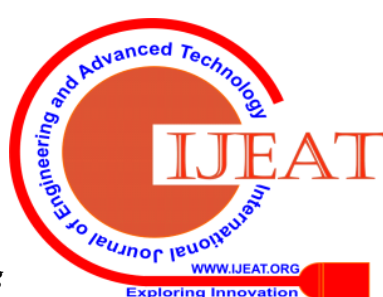


When adjusting for the formula for height, the wood stock on the trial plot was $82.7 \mathrm{~m}^{3} / \mathrm{ha}$.

The results were checked at several test plots on the ground. Maximum error in the calculation of the stock was $15 \%$. This error is acceptable when assessing the forest resources in accordance with standards in forestry.

\section{DISCUSSION}

The volumetric functionality presented in modern software products designed for thematic processing of remote sensing data does not guarantee the rapid receipt of accurate and reliable information about the territory. In most cases, the development of specialized methods and algorithms aimed at solving a specialized problem is required. One such example is the method presented in the article for obtaining data of wood stock from the UAVs data.

The methodology described in the article will significantly accelerate the process of thematic interpretation and updating of data on forest resources, increase the reliability of information about forests due to new methods of processing aerospace images.

\section{CONCLUSION}

Thus, in the presented article, the authors describe a methodology for updating forest resources data based on aerial survey data.

The methodology includes approaches related to the allocation of tree crowns, identification of species and wood stock. It will be useful for automating the process of images with spatial resolution of 5-10 centimeters per pixel. The experiments presented in the article were carried out on images of forests in the north of the European part of Russia.

In the future, it is supposed to continue research in the direction of developing algorithms for separating crown complexes into single crowns, using compact multispectral cameras for reliable determination of forest species.

\section{ACKNOWLEDGMENT}

Sections A and B of the Methodology were completed by Roman Aleshko with the support of grant from Russian Science Foundation (project 19-71-00040) at Northern (Arctic) Federal University.

\section{REFERENCES}

1. Sukhikh V.I. Aerokosmicheskie metody v lesnom khozyaistve landshaftnom stroitelstve (Aerospace methods in forestry and landscape construction), Ioshkar-Ola: MarGTU, 2005, 392 p.

2. Franklin S.E. Remote Sensing for Sustainable Forest Management, CRC Press, 1 edition, June 2001, 424 p.

3. Wulder M.A., Franklin S.E. Understanding Forest Disturbance and Spatial Pattern: Remote Sensing and GIS Approaches, CRC Press, 1 edition, July 2006, 246 p.

4. Potapov, P., Hansen, M. C., Stehman, S. V., Loveland, T. R., \& Pittman, K. (2008). Combining MODIS and Landsat imagery to estimate and map boreal forest cover loss. Remote Sensing of Environment, 112(9), 3708-3719.

5. Berterretche, M., Hudak, A. T., Cohen, W. B., Maiersperger, T. K., Gower, S. T., \& Dungan, J. (2005). Comparison of regression and geostatistical methods for mapping Leaf Area Index (LAI) with Landsat ETM+ data over a boreal forest. Remote Sensing of Environment, 96(1), 49-61.

6. Ranson, K. J., Kovacs, K., Sun, G., \& Kharuk, V. I. (2003). Disturbance recognition in the boreal forest using radar and Landsat-7. Canadian journal of remote sensing, 29(2), 271-285.
7. Korhonen, L., Packalen, P., \& Rautiainen, M. (2017). Comparison of Sentinel-2 and Landsat 8 in the estimation of boreal forest canopy cover and leaf area index. Remote sensing of environment, 195, 259-274.

8. Schroeder, T. A., Wulder, M. A., Healey, S. P., \& Moisen, G. G. (2011) Mapping wildfire and clearcut harvest disturbances in boreal forests with Landsat time series data. Remote Sensing of Environment, 115(6), 1421-1433.

9. Dietmaier, A., McDermid, G. J., Rahman, M. M., Linke, J., \& Ludwig, R. (2019). Comparison of LiDAR and digital aerial photogrammetry for characterizing canopy openings in the Boreal Forest of Northern Alberta. Remote Sensing, 11(16), 1919.

10. Kukkonen, M., Maltamo, M., Korhonen, L., \& Packalen, P. (2019) Multispectral airborne LiDAR data in the prediction of boreal tree species composition. IEEE Transactions on Geoscience and Remote Sensing, 57(6), 3462-3471.

11. Taheriazad, L., Moghadas, H., \& Sanchez-Azofeifa, A. (2019). Calculation of leaf area index in a Canadian boreal forest using adaptive voxelization and terrestrial LiDAR. International Journal of Applied Earth Observation and Geoinformation, 83, 101923.

12. Montgomery, J., Brisco, B., Chasmer, L., Devito, K., Cobbaert, D., \& Hopkinson, C. (2019). SAR and LiDAR temporal data fusion approaches to boreal wetland ecosystem monitoring. Remote Sensing, 11(2), 161.

13. Guriev A.T., Aleshko R.A. Adapting the combined database of cartographic and attribute information of forest plantations by automating remote sensing data interpretation, Earth From Space - The most effective solutions, Research and development center ScanEx, Transparent world, BKL Publishers, 2009, p. 233-234.

14. Aleshko R.A., Guriev A.T., Shoshina K.V., Schenikov V.S Development of methodology for visualization and processing of geospatial data, Scientific Visualization, 2015, Vol. 7, Issue 1, pp 20-29

15. Aleshko, R. A., Guriev, A. T., Shoshina, K. V., \& Schenikov, V. S. (2015). Development of methodology for visualization and processing of geospatial data. Scientific Visualization, 7(1), 20-29.

16. Bogdanov, A. P., Karpov, A. A., Demina, N. A., \& Aleshko, R. A. (2018). Improving forest monitoring by using cloud technologies as an element of sustainable forest management. Sovremennye Problemy Distantsionnogo Zondirovaniya Zemli Iz Kosmosa, 15(1), 89-100. doi:10.21046/2070-7401-2018-15-1-89-100

17. Edward R. Dougherty, Roberto A. Lotufo Hands-on Morphological Image Processing, SPIE Press, 2003, Technology \& Engineering, 272 p.

18. K. Parvati, B. S. Prakasa Rao, and M. Mariya Das Image Segmentation Using Gray-Scale Morphology and Marker-Controlled Watershed Transformation, Discrete Dynamics in Nature and Society, Vol. 2008, Article ID 384346, 2008, doi:10.1155/2008/384346

19. Gao H., Xue P., Lin W. A new marker-based watershed algorithm, Circuits and Systems, 2004, ISCAS '04. Proceedings of the 2004 International Symposium, Volume 2, May 2004, pp. 81-84

20. Kuzmichev V.V. Regularities of forest stands growth. Novosibirsk: Nauka, 1977, $160 \mathrm{p}$

21. Gusev I.I. Taxation of trunk of felled or growing tree. Tutorial, Arkhangelsk: Izdatelstvo ALTI, 1992, 80 p.

\section{AUTHORS PROFILE}

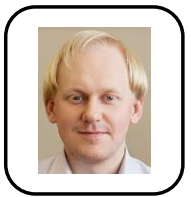

Roman Aleshko, Associate Professor at Northern (Arctic) Federal University, Candidate of Sciences in Computer Science.

Specialist in digital image processing, aerospace monitoring, development of methods and algorithms.

Experience in managing and participating in research projects: Development of models of structural interrelationships of elements in complex systems aerospace survey data and ground objects using systems analysis methods, Creating a methodology for interpreting multispectral aerial photographs of superhigh resolution based on an ontological approach, Creation of methods for automated determination of forest resource parameters using multispectral survey data from an unmanned aerial vehicle and others.

Scientific management of the Master program "Geoinformation technologies".

Scientific awards: Award of the President of the Russian Federation to young scientists and postgraduates.

Has more than 50 papers. 


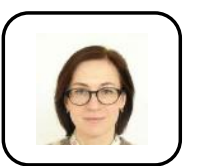

Ksenia Shoshina Candidate of Technical Sciences in Computer Science, Associate Professor of the Department of Information Systems and Technologies, Northern (Arctic) Federal University. Her areas of research are methods and technologies for image processing and analysis. She has numerous research articles and participation in national and international conferences.

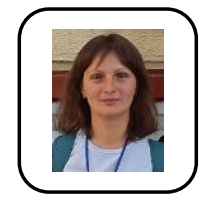

Irina Vasendina, Senior Lecturer at Information Systems and Technologies Department, Northern (Arctic) Federal University. She received her degree of candidate of technical sciences in System analysis, management and information processing in Moscow State Technological University "STANKIN". Her publications are devoted to the problem of structuring heterogeneous information about vegetation objects, as well as to obtaining this information through thematic interpretation of images of the Earth's surface. The author has developed a method for processing information about objects of northern ecosystems based on structural modeling, which allows one to obtain multi-aspect information about objects of vegetation cover using artificial intelligence methods. Her current research interests include systems analysis, process control, automation, image processing, neural networks, deep learning, and segmentation of highly detailed images.

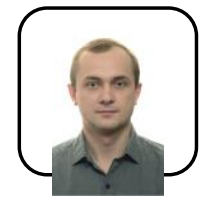

Aleksandr Bogdanov, graduated from the Northern (Arctic) Federal University named after M.V. Lomonosov Institute of forestry (2011). Senior Researcher at the research department, "Northern research institute of forestry" (NRIF), candidate of agricultural sciences on a specialty "forestry, forest management and forest assessment" (2014), assistant professor at the Department of the Forest Assessment and Management NArFU named M.V. Lomonosov (2016). A specialist in the field of sustainable forest management, forest inventory, remote sensing. Head and supervisor for a research projects, directed to consulting companies on sustainable forest management and remote monitoring of forest. Author (and co-author) of more than 50 papers, including one monograph.

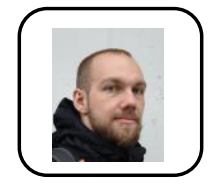

Aleksandr Karpov, PhD student, has completed master's degree in Geoinformatics in the Department of Computer Science and continued education at $\mathrm{PhD}$ level in the Forestry Department of the Northern (Arctic) Federal University. The topic of his research is monitoring of reforestation using remote sensing technologies. This topic requires knowledge of both forest sphere and computer science. Aleksandr had an internship in Osnabrück University in Germany in the Department of Computer Science for half a year. The topic of his research here is monitoring of the Arkhangelsk Region forest using a multisensory approach. This research focuses on the monitoring of deforestation and reforestation processes. He was head of project "Improvement of monitoring of forest reproduction by remote methods as an element of sustainable forest management in the Arctic zone of the Arkhangelsk region" supported by ministry of science and education of Arkhangelsk region. Aleksandr has experience as a GIS specialist, forest researcher and he has skills in fieldwork and processing satellite imagery. 